\title{
Visual body-scores selection and its influence on body size and ultrasound carcass traits in Nellore cattle ${ }^{1}$
}

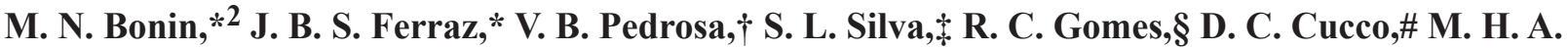 \\ Santana,* J. H. A. Campos, * V. N. Barbosa,* F. S. F. Castro,* F. J. Novais, * and E. C. M. Oliveira* \\ *Department of Veterinary Medicine, College of Animal Science and Food Engineering, University \\ of São Paulo, Pirassununga, São Paulo 13635-900, Brazil; †Department of Animal Science, Ponta Grossa \\ State University, Ponta Grossa, Paraná 84030-000, Brazil; \$Department of Animal Science, College of Animal \\ Science and Food Engineering, University of Sao Paulo, Pirassununga, Sao Paulo 13635-900, Brazil; §Embrapa \\ Beef Cattle, Brazilian Agricultural Research Corporation, Campo Grande, Mato Grosso do Sul 79106-550, Brazil; \\ and \#Department of Animal Science, Santa Catarina State University, Chapeco, Santa Catarina 89815-630, Brazil
}

\begin{abstract}
Genetic parameters, genetic trends, and genetic progress of carcass traits were estimated for 12,447 Nellore individuals from different Brazilian herds. The following carcass traits were analyzed: visual body scores of conformation (CONF), precocity (PREC), and muscularity (MUSC); rump width (RW) and rump length (RL), body size (frame); and ultrasound evaluation of ribeye area (REA), backfat thickness (BFT), and rump fat thickness (RFT). Heritability estimates $( \pm$ SE) for CONF, PREC, and MUSC were $0.23 \pm$ $0.02,0.33 \pm 0.03$, and $0.31 \pm 0.02$, respectively. The heritability estimates $( \pm \mathrm{SE})$ for RW, RL, and frame were $0.25 \pm 0.05,0.16 \pm 0.04$, and $0.31 \pm 0.03$, respectively. Ultrasound of the REA, BFT, and RFT presented mean heritability estimates $( \pm$ SE) of $0.38 \pm 0.03,0.44 \pm 0.04$, and $0.47 \pm 0.04$, respectively. The visual body score of CONF had high genetic correlations with RW, RL, and frame $(0.74 \pm 0.09,0.82 \pm 0.08$, and $0.83 \pm 0.04$, respectively), indicating a high association of CONF with the measurements related to body structure. The REA had no correlation with BFT and RFT (-0.09 \pm 0.04 and $-0.03 \pm 0.04$, respectively) and showed only a
\end{abstract}

moderate genetic correlation with MUSC $(0.39 \pm 0.05)$. The BFT and RFT had moderate genetic correlations with PREC $(0.36 \pm 0.07$ and $0.29 \pm 0.07$, respectively) and no correlation with frame $(-0.02 \pm 0.03$ and $0.05 \pm$ 0.05 , respectively), suggesting that selection for frame had no effect on the subcutaneous fat content of the carcass. Low genetic trends and low genetic progress were obtained for REA $\left(0.026 \mathrm{~cm}^{2}, 0.02 \%\right)$, BFT $(0.0031$ $\mathrm{mm}, 0.05 \%)$, and RFT (0.0013 $\mathrm{mm}, 0.02 \%)$, with no significant values of genetic progress detected throughout the studied period. The CONF, PREC, and MUSC presented high genetic trends ( 0.030 points, 0.030 points, and 0.029 points, respectively) and high genetic progress $(0.60 \%, 0.56 \%$, and $0.59 \%$, respectively), indicating a significant genetic progress for these traits throughout the evaluated period. Carcass traits evaluated by ultrasound and visual body scores are eligible for selection and can be used in genetic improvement programs in Nellore cattle; however, visual body score selection for carcass traits can result in slower genetic progress for carcass quality when compared to selection performed by ultrasound.

Key words: Bos indicus, frame, genetic parameters, ribeye area, rump fat thickness, rump measurements

(C) 2015 American Society of Animal Science. All rights reserved.

\footnotetext{
${ }^{1}$ Data first presented to the Animal Science Post-Graduate Program, College of Animal Science and Food Engineering, University of São Paulo (FZEA-USP). This research received financial support from the Fundação de Amparo à Pesquisa do Estado de São Paulo (FAPESP) that also provided the grants 2009/15930-8 and 2009/01357-4 to J. B. S. Ferraz and M. N. Bonin, respectively.

${ }^{2}$ Corresponding author: marinabonin@hotmail.com

Received May 7, 2015.

Accepted September 20, 2015.
}

J. Anim. Sci. 2015.93
doi: $10.2527 /$ jas2015-9280

\section{INTRODUCTION}

Zebu cattle (Bos indicus) have been bred intensively in tropical countries because of their greater adaptability to these regions. It is estimated that about $40 \%$ of the world's current cattle herd comprises Zebu cattle and their crosses (USDA, 2015). A large proportion of the herds from large meat exporters, such 
as Brazil and India, are composed of Zebu cattle, demonstrating the importance of genetic improvement of these animals for beef production. In Brazil, breeding programs have mainly focused on growth traits such as weight gain (Santiago, 1987) because they are easy to measure and are economically relevant. However, the selection of herds based on growth characteristics may lead to an increase in body size with little or no associated effect on carcass quality, despite the clear need for improvement in meat quality and retail product yield in Zebu breeds (Pereira et al., 2001; Shiotsuki et al., 2009; Pereira et al., 2010; Yokoo et al., 2010). Furthermore, the selection for carcass quality has been widely based on the visual assessment of body scores because of the low cost and ease of application (May et al., 1992; Wilson, 1992; Koury Filho et al., 2010; Pinheiro et al., 2011). Ultrasound scanning is a more accurate option but is used less because of the cost. In this context, comparing the genetic improvement obtained for carcass quality using visual body scores and ultrasound traits will contribute valuable information to the current strategies adopted by breeding programs in countries where Zebu cattle are economically relevant. Hence, the aim of this study was to evaluate the effectiveness of using visual body scores and ultrasound measurements of carcass traits in the selection for carcass quality in Nellore cattle.

\section{MATERIALS AND METHODS}

Animal Care and Use Committee approval was not necessary for this study because the data were obtained from an existing database supplied by the Nucleus of Research Support in Genetics, Biotechnology, and Transgenesis-NAP-GMABT (Pirassununga, Brazil).

\section{Animals and Data}

Data were obtained from 3 commercial herds of the Nellore breed in Brazil between 1997 and 2009. The database comprised information on 12,447 feedlotfinished Nellore bulls, 21 to 24 mo of age, raised in Brachiaria sp. and Panicum sp. grazing systems. The herds were selected based on the bioeconomic selection index proposed by Brumatti et al. (2011), with a selection pressure of $20 \%$ and a generation interval of $5 \mathrm{yr}$.

Cattle were evaluated using: visual body scoresconformation (CONF), precocity (PREC), and muscularity (MUSC); rump measurements: rump width (RW), rump length (RL), and hip height $(\mathbf{H H})$; and ultrasound of the carcass traits measurements: ribeye area (REA), backfat thickness (BFT), and rump fat thickness (RFT).

Conformation, precocity, and muscularity scores were based on the Ankony system proposed by Long (1971), with some modifications. Visual body scores were evaluated on a scale from 1 to 6 points by trained technicians, and they were intended to estimate body structure and carcass composition. Conformation evaluates the depth, width, and length of the animal's body; precocity is related to the subcutaneous fat scores and fat deposition on the carcass at sites such as the tail tip and breast, and it reflects the flank and lower ribs. According to Boligon et al. (2011), animals with deeper ribs, large rib cage, a full silhouette, and the onset of subcutaneous fat deposition, mainly at the base of the tail, are earlier finishing. Tall and thin, extremely lean animals with a shallow rib cage and the silhouette of a gazelle are considered to be late precocity of finishing cattle. The muscularity is related to the muscle development of the animal at several reference sites including shoulder, loin, rump, and in the hindquarter (Boligon et al., 2011).

Hip height, rump width, and rump length were measured using a ruler, following a method described by Oliveira et al. (2013). Hip height measurements were taken at the anatomical point directly over the hip bones (hocks); rump width was determined as the distance between the ilia, and rump length as the distance between the ilium and ischium. These measurements allowed us to assess the correlation between the dimensions of the animal's rump and its muscularity obtained from the muscularity visual score and from the ultrasound evaluation of the ribeye area.

The hip height $(\mathbf{H H})$ and live weight $(\mathbf{L W})$ at 18 mo of age were used for estimating body size (frame) using the Nellore cattle specific equation proposed by Horimoto et al. (2006), defined as follows:

$$
\begin{aligned}
& \text { Frame }=-7.01993+0.06294 \times H H-0.14870 \times \\
& L W+0.00119 \times H H \times L W
\end{aligned}
$$

where $H H=$ hip height $(\mathrm{cm})$ and $L W=$ live weight $(\mathrm{kg})$.

Carcass ultrasound evaluations were performed by trained field technicians and followed the standards set by the Ultrasound Guidelines Council (UGC; www. ultrasoundbeef.com). An Aloka SSD 500 Micrus ultrasound (Aloka Co. Ltd, Wallingford, CT) equipped with a 172-mm-long linear transducer with a frequency of 3.5 MHz was used. Measurements of the ribeye area and backfat thickness were obtained from sectional images of the LM between the 12th and 13th rib. The rump fat thickness was measured by positioning the transducer in the final third of the ilium and recording an image at the joint between the biceps femoris and the gluteus medius muscle. Ultrasound pictures were taken and stored using an image capture system (UICS; Walter \& Associates, LLC, Ames, IA) and subsequently analyzed by certified laboratory technicians, who are responsible for the quality of the data. 
Table 1. Descriptive statistics, genetic, environmental, and phenotypic variances, and heritability estimates for visual body scores, carcass traits evaluated by ultrasound, and frame in Nellore cattle

\begin{tabular}{|c|c|c|c|c|c|c|c|}
\hline \multirow[b]{2}{*}{ Trait } & \multirow[b]{2}{*}{ Evaluation method } & \multicolumn{2}{|c|}{ Descriptive statistics ${ }^{1}$} & \multicolumn{3}{|c|}{ Variances $^{2}$} & \multirow{2}{*}{$\frac{\text { Heritability }^{3}}{h_{a}^{2} \pm S E}$} \\
\hline & & $\mathrm{N}$ & Mean \pm SD & $\sigma_{a}^{2}$ & $\sigma_{e}^{2}$ & $\sigma_{p}^{2}$ & \\
\hline Rump width, cm & Ruler & 3622 & $41.20 \pm 2.33$ & 0.77 & 2.30 & 3.08 & $0.25 \pm 0.05$ \\
\hline Rump length, $\mathrm{cm}$ & Ruler & 3623 & $44.23 \pm 2.93$ & 0.49 & 2.60 & 3.09 & $0.16 \pm 0.04$ \\
\hline Ribeye area, $\mathrm{cm}^{2}$ & Ultrasound & 9567 & $61.24 \pm 14.17$ & 14.76 & 24.43 & 39.19 & $0.38 \pm 0.03$ \\
\hline Backfat thickness, mm & Ultrasound & 9567 & $2.77 \pm 1.59$ & 0.51 & 0.66 & 1.18 & $0.44 \pm 0.04$ \\
\hline Rump fat thickness, mm & Ultrasound & 9567 & $3.77 \pm 2.84$ & 1.25 & 1.40 & 2.66 & $0.47 \pm 0.04$ \\
\hline Conformation, points & Visual scores & 11639 & $3.57 \pm 1.46$ & 0.17 & 0.60 & 0.78 & $0.23 \pm 0.02$ \\
\hline Precocity, points & Visual scores & 11639 & $3.79 \pm 1.43$ & 0.30 & 0.61 & 0.91 & $0.33 \pm 0.03$ \\
\hline Muscularity, points & Visual scores & 11639 & $3.59 \pm 1.44$ & 0.27 & 0.61 & 0.89 & $0.31 \pm 0.02$ \\
\hline Frame, units & Equation & 10625 & $7.68 \pm 2.88$ & 0.86 & 2.05 & 2.91 & $0.31 \pm 0.03$ \\
\hline
\end{tabular}

${ }^{1}$ Descriptive statistics: $N=$ number of animals evaluated; Mean $=$ the mean of the trait; $\mathrm{SD}=$ standard deviation.

${ }^{2}$ Variances: $\sigma_{a}^{2}=$ genetic variance; $\sigma_{e}^{2}=$ environmental variance; $\sigma_{p}^{2}=$ phenotypic variance.

${ }^{3} h_{a}^{2}=$ heritability estimates; $\mathrm{SE}=$ standard error.

Only visual body scores were used for selection of carcass quality in the evaluated herds. Ultrasound evaluations were performed only for monitoring the genetic progress of carcass traits selected visually.

\section{Genetic Parameters}

Multitrait analyses were performed using PEST (Groeneveld, 2006) and VCE 6.0 (Neumaier and Groeneveld, 1998; Groeneveld et al., 2008) softwares. Breeding values and genetic parameters were estimated according to a mixed-model methodology, based on the animal model proposed by Henderson (1975) and using a pedigree matrix composed of 23,185 animals.

Contemporary groups were defined as groups of animals of the same sex, reared within a management group and born in the same herd and year. Contemporary groups containing progeny of only 1 sire or fewer than 3 animals were excluded. In addition, phenotypic information with SD values equal to or larger than 3 was discarded.

Initial computations were performed using SAS Proc GLM (SAS Inst. Inc., Cary, NC) to evaluate the effects that were included in the model $(P<0.05)$. The contemporary group formed by the adjusted age (18 mo) was used as a fixed effect for conformation, precocity, and muscularity evaluation. For the ultrasound traits, the fixed effects were the contemporary group formed by the occasion of measurement, the field technicians, age, and time spent in the feedlot before slaughter.

The general model used for the multitraits analysis was

$$
y=X \beta+Z a+e,
$$

where $y=$ vector of dependent variables, $\beta=$ vector of fixed effects, $a=$ vector of random effects, $e=$ vector of random residual effects, and $X$ and $Z=$ incidence matrices relating to fixed and random genetic effects, respectively.

Genetic trends were estimated from the annual averages of animal breeding values. Based on these values, the average breeding value in relation to the year of birth of the animal was calculated according to the regression model:

$$
\hat{Y} k=b_{0}+b_{1} X_{k}
$$

where $\hat{Y}=$ the average genetic value of birth year, $\mathrm{b}_{0}=$ constant of the equation, $b_{1}=$ linear coefficient regression, and $X_{k}=$ birth year. Thus, the annual genetic improvement for the characteristics evaluated in this study was estimated using linear regression.

\section{RESULTS}

Descriptive statistics, variance components, and heritability estimates of the traits evaluated in this study are presented in Table 1.

\section{Heritability}

Heritability of the traits reported in this study is consistent with the literature, ranging from moderate to high (Table 1). The lowest estimates were found for rump width and rump length and the highest for backfat thickness and rump fat thickness. All traits are therefore eligible for selection, with ultrasound fat thickness showing the highest possibility for genetic progress as these traits presented heritability greater than 0.4 . 
Table 2. Genetic and phenotypic correlations for visual body scores, carcass traits evaluated by ultrasound, rump measurements, and frame in Nellore cattle ${ }^{1}$

\begin{tabular}{|c|c|c|c|c|c|c|c|c|c|}
\hline \multirow[b]{2}{*}{ Trait $^{2}$} & \multicolumn{9}{|c|}{ Trait $^{2}$} \\
\hline & RW & $\mathrm{RL}$ & REA & BFT & RFT & CONF & PREC & MUSC & Frame \\
\hline$\overline{\mathrm{RW}}$ & & $0.81 \pm 0.10$ & $0.42 \pm 0.12$ & $0.51 \pm 0.13$ & $0.40 \pm 0.11$ & $0.74 \pm 0.09$ & $0.39 \pm 0.10$ & $0.40 \pm 0.11$ & $0.74 \pm 0.09$ \\
\hline RL & $0.43 \pm 0.07$ & & $0.37 \pm 0.12$ & $0.44 \pm 0.11$ & $0.27 \pm 0.11$ & $0.82 \pm 0.08$ & $0.39 \pm 0.11$ & $0.35 \pm 0.12$ & $0.87 \pm 0.07$ \\
\hline REA & $0.18 \pm 0.08$ & $0.15 \pm 0.06$ & & $-0.09 \pm 0.04$ & $-0.03 \pm 0.04$ & $0.22 \pm 0.09$ & $0.35 \pm 0.06$ & $0.39 \pm 0.05$ & $0.16 \pm 0.05$ \\
\hline BFT & $0.12 \pm 0.07$ & $0.03 \pm 0.01$ & $0.08 \pm 0.03$ & & $0.64 \pm 0.04$ & $0.18 \pm 0.09$ & $0.36 \pm 0.07$ & $0.35 \pm 0.07$ & $-0.02 \pm 0.03$ \\
\hline RFT & $0.13 \pm 0.05$ & $0.01 \pm 0.01$ & $0.04 \pm 0.01$ & $0.51 \pm 0.11$ & & $0.18 \pm 0.09$ & $0.29 \pm 0.07$ & $0.25 \pm 0.07$ & $0.05 \pm 0.05$ \\
\hline CONF & $0.33 \pm 0.07$ & $0.27 \pm 0.06$ & $0.24 \pm 0.04$ & $0.09 \pm 0.03$ & $0.09 \pm 0.06$ & & $0.73 \pm 0.03$ & $0.72 \pm 0.04$ & $0.83 \pm 0.04$ \\
\hline PREC & $0.26 \pm 0.03$ & $0.15 \pm 0.03$ & $0.29 \pm 0.06$ & $0.13 \pm 0.02$ & $0.13 \pm 0.03$ & $0.67 \pm 0.06$ & & $0.98 \pm 0.01$ & $0.31 \pm 0.07$ \\
\hline MUSC & $0.23 \pm 0.03$ & $0.14 \pm 0.02$ & $0.29 \pm 0.03$ & $0.12 \pm 0.01$ & $0.12 \pm 0.01$ & $0.66 \pm 0.02$ & $0.89 \pm 0.04$ & & $0.32 \pm 0.07$ \\
\hline Frame & $0.38 \pm 0.04$ & $0.35 \pm 0.03$ & $0.16 \pm 0.03$ & $0.05 \pm 0.02$ & $0.06 \pm 0.01$ & $0.48 \pm 0.05$ & $0.30 \pm 0.04$ & $0.28 \pm 0.08$ & \\
\hline
\end{tabular}

${ }^{1}$ Genetic correlations ( \pm SE) are presented above and phenotypic correlations $( \pm \mathrm{SE})$ under the diagonal.

${ }^{2}$ Traits: $\mathrm{RW}=$ rump width $(\mathrm{cm}) ; \mathrm{RL}=$ rump length $(\mathrm{cm}) ; \mathrm{REA}=$ ribeye area $\left(\mathrm{cm}^{2}\right) ; \mathrm{BFT}=$ backfat thickness $(\mathrm{mm}) ; \mathrm{RFT}=$ rump fat thickness $(\mathrm{mm})$; $\mathrm{CONF}=$ conformation (points); $\mathrm{PREC}=$ precocity (points); $\mathrm{MUSC}=$ muscularity (points), Frame $=$ body size, units.

\section{Genetic Correlations}

Genetic correlations are presented in Table 2. High correlations (up to 0.70) were found between conformation and rump width, rump length, and frame. Rump width presented a moderate correlation with ultrasound fat thickness. In contrast, the correlation of rump length with backfat thickness and rump fat thickness was low. Rump measurements had low correlations with precocity and muscularity, indicating they could be more related to body size itself than to cattle finishing and the muscular portion of the animal.

Ribeye area was not correlated with backfat thickness or rump fat thickness (values close to zero) and showed a low correlation with conformation and frame and a moderate correlation with precocity and muscularity. Backfat thickness and rump fat thickness were highly correlated with each other, but low correlations were found between backfat thickness and conformation, precocity, muscularity, and frame (Table 2).

Visual body scores were highly correlated among themselves, particularly precocity and muscularity, suggesting that fat and muscle masses might be confused during evaluation. The correlation between conformation and frame was also high, indicating a high degree of dependency between the traits measuring body structure.

\section{Genetic Progress}

The genetic trends and genetic progress of the traits are presented in Fig. 1 to 3. With the exception of the frame, the genetic trends of all traits were positive and different from zero, demonstrating a genetic evolution for the traits during the study period. The rump traits (Fig. 1) presented genetic progress close to zero during the same period. Genetic trends for ribeye area, backfat thickness, and rump fat thickness were low, with values equal or lower than $0.05 \%$ over the evaluated period
(Fig. 2). High genetic progress (values over $0.5 \%$ ) was observed for conformation, precocity, and muscularity (Fig. 3). In general, rump measurements, frame, and ultrasound measurements of carcass traits showed null genetic progress throughout the evaluation period.

\section{DISCUSSION}

\section{Heritability}

Heritability estimates indicate the genetic proportion of the trait and how much of its phenotypic variation is due to the effects of additive genes (Buchanan and Clutter, 1989). Thus, the greater the heritability estimates, the greater the proportion of the phenotypic expression of the trait attributed to genetic variance.

Heritability values found were above 0.20 , with the exception of rump length, suggesting that growth and carcass traits might present a significant genetic evolution if selected properly. In this study, the greatest heritability values were obtained for ultrasound carcass traits and the lowest for body measurements and visual body scores. Objective measurements such as ultrasound evaluations, when properly collected and interpreted, are less prone to errors from environmental interference than visual body assessments (Faria et al., 2009). Visual body score assessments are subjective and could be more affected by environmental aspects related to technician experience, contemporary group characteristics, and body fat. These aspects may have led to the low accuracy of trait estimates such as muscularity.

The addition of repeated measurements may add greater precision to results, which was not done in the present work. Pinheiro et al. (2011) suggested that traits measured in the same animal over a period of time increase the accuracy of prediction of the breed- 
RW

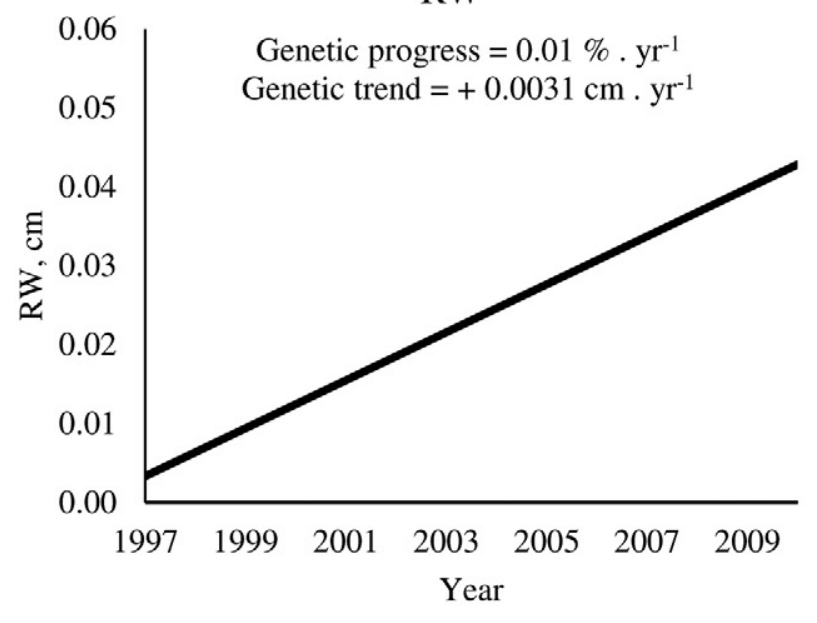

RL

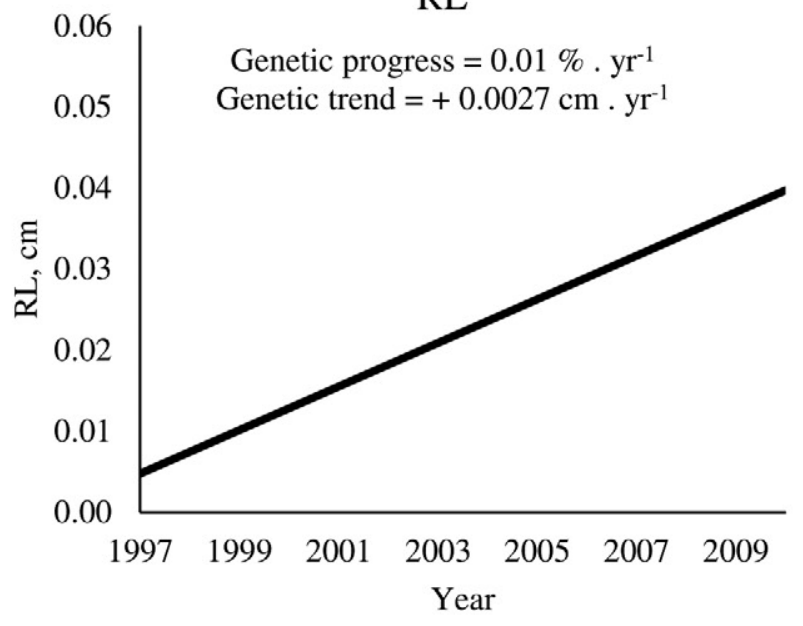

Frame



Figure 1. Genetic progress and genetic trend for rump width (RW), rump length (RL), and body size (Frame) in Nellore herds.
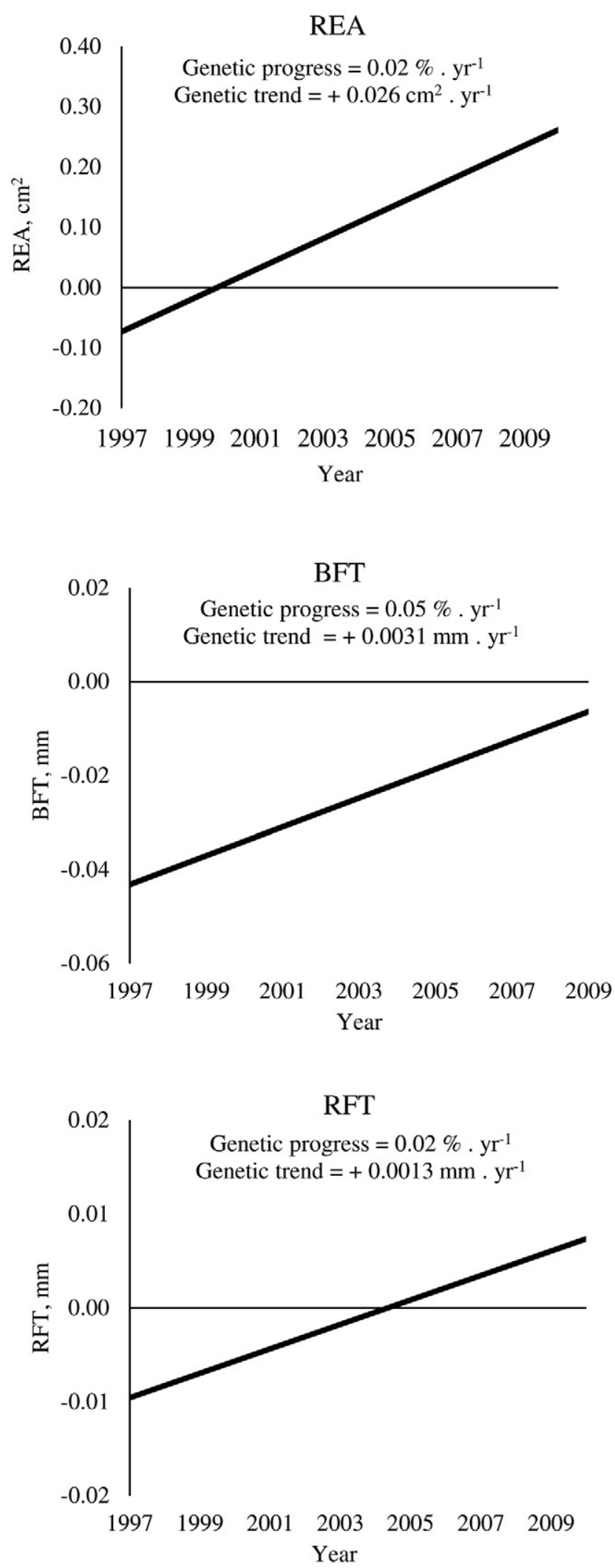

Figure 2. Genetic progress and genetic trend for ribeye area (REA), backfat thickness (BFT), and rump fat thickness (RFT) as evaluated by ultrasound in Nellore herds. 

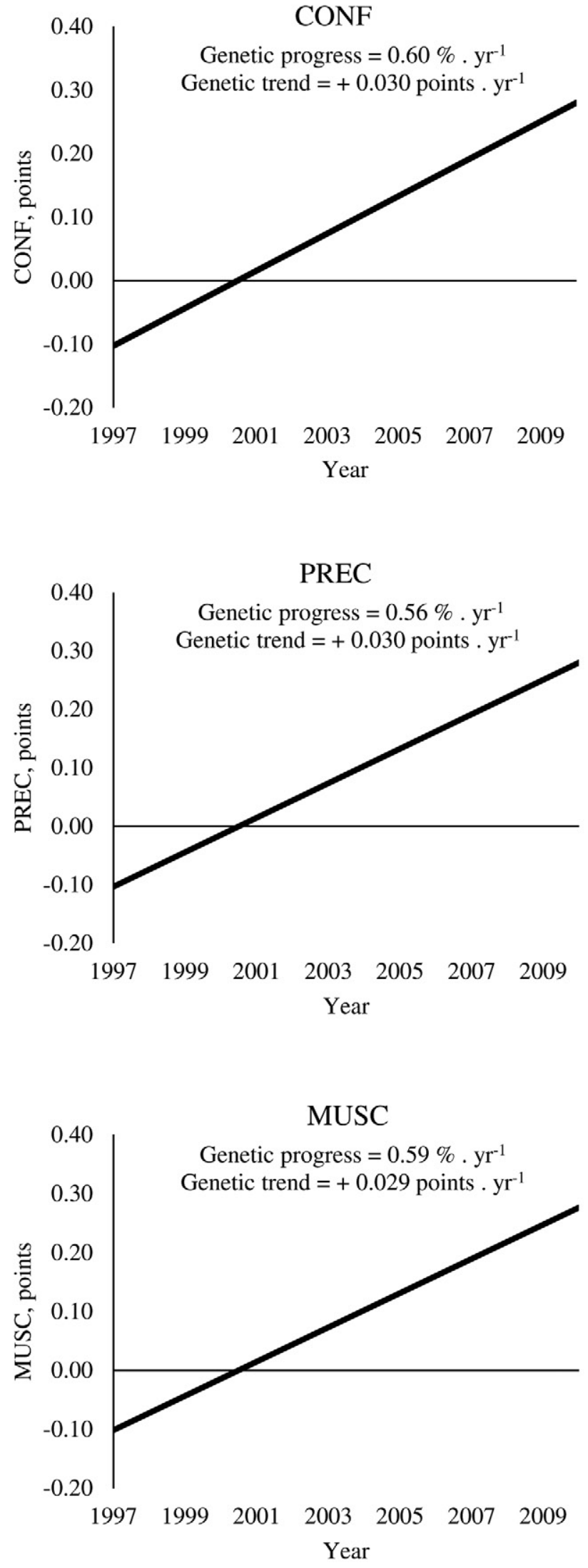

Figure 3. Genetic progress and genetic trend for visual body scores of conformation (CONF), precocity (PREC), and muscularity (MUSC) in Nellore herds. ing values. According to Falconer and Mackey (1996) and Pinheiro et al. (2011), not only permanent differences between individuals, but also differences caused by the temporary environment contribute to total phenotypic variance and can only be analyzed within and between individuals when repeated measures of the same trait are obtained from each individual.

Therefore, to ensure quality of the information generated, especially for the traits used in genetic improvement programs, it is important that qualified technicians perform ultrasound and visual body score traits and that the measures are obtained in the same animal over time. Such an approach allows us to estimate the covariance between traits and to determine whether the measures present sufficient repeatability (Perkins et al., 1992; Pinheiro et al., 2011; UGC, 2012).

In this study, carcass traits such as ribeye area, backfat thickness, and rump fat thickness presented moderate values of heritability. In 2013, Marques et al. (2013) found a high value of heritability for the ribeye area (0.66) in Nellore animals. This value was greater than the average values reported in the literature for the Nellore breed, which vary from 0.33 to 0.46 (Yokoo et al., 2008; Pinheiro et al., 2011; Bonin, 2012; Caetano et al., 2013), and by Robinson et al. (1993) for Hereford animals $(0.18-0.20)$. For backfat thickness, the heritability value found here was similar to the value of 0.50 found by Yokoo et al. (2010) in Nellore animals. For rump fat thickness, the value was greater than those previously reported for this breed (Yokoo et al., 2010; Zuin et al., 2012; Caetano et al., 2013) and closer to that reported for the Angus breed, as described by Robinson et al. (1993). A large variation in carcass trait heritability has been observed in the Nellore breed due to the influence of different lineages (Bonin et al., 2014), which could explain the differences found between the present study and the values reported in the literature. Another possible explanation is the different statistical methodologies adopted among different researches, such as the inclusion of maternal effects, permanent environmental effects, repeatability, or genetic groups.

Subcutaneous fat is important for preventing cold shortening, which could result in tougher meat (Koohmaraie et al., 1988; Thompson, 2002; King et al., 2003), further exacerbating the problems of low tenderness found in Zebu animals (McKeith et al., 1985; Crouse et al., 1989; Whipple et al., 1990; Sherbeck et al., 1996; Wulf and Page, 2000; Burrow et al., 2001; Riley et al., 2005). In general, Brazilian abattoirs have a high daily slaughter capacity (approximately 2,000 animals per day) and need a high turnover rate. Therefore, slaughtered animals have to be placed in low-temperature and high-air-speed cooling chambers until they are sold. This procedure aggravates the effects of cold on 
meat quality, particularly in animals with low fat thickness. Considering the moderate to high heritability of backfat and rump fat thickness in the Nellore breed and the importance of these characteristics in determining meat quality, the need to include these traits in genetic improvement programs of Nellore cattle becomes clear.

Body measurements such as rump width, rump length, and frame are indicative of body size, being widely used for the control of adult size (Faria et al., 2009; BIF, 2010). The selection for growth traits such as live weight gain and ribeye area can lead to an increase in conformation and, consequently, in frame (Horimoto et al., 2007; Koury Filho et al., 2010; Pereira et al., 2010). Because these traits have a moderate heritability, their selection might lead to an increase in herd's mature weight and maintenance requirements (Berg and Butterfield, 1976; Riley et al., 2002; Yokoo et al., 2007). Therefore, selection of these traits should be controlled, especially by observing their genetic progress in the herd.

\section{Genetic Correlations}

The high genetic correlations of rump width and rump length with conformation and frame are explained by the fact that both traits are based on measurements of skeleton structure. Hence, visual body scores of conformation can be good indicators of body size and can be used to control the herd's mature weight.

Faria et al. (2009), in their evaluation of Nellore animals aged $22 \mathrm{mo}$, found that hip height was highly correlated with conformation (0.63) and physical structure (0.71). Genetic correlations of rump width and rump length with ribeye area, backfat thickness, precocity, and muscularity suggest that similar groups of genes determine rump traits, muscling, and fat deposition. In addition, the high correlations between conformation, precocity, and muscularity revealed a high dependency between these traits. Koury Filho et al. (2010) also reported high genetic correlations (above 0.70 ) between these traits for the Nellore cattle.

Genetic correlations between conformation, precocity, muscularity, and ultrasound carcass traits were moderate to low, reaching values below 0.40 . Conversely, the high associations between muscularity and ribeye area and among precocity, backfat thickness, and rump fat thickness were expected, as the objective of evaluating these traits is to assess carcass characteristics such as muscle and backfat deposition.

Precocity and rump fat thickness measurements have the same objective, i.e., to evaluate cattle-finishing precocity as, according to Lawrence and Fowler (2002), the deposition of body fat begins in the rump and abdominal areas and ends in the region between the loin and the last rib. Based on this concept, high correlations between precocity and rump fat thickness were expected; however, this did not occur.

Ultrasound is a well-established technique for evaluation of bovine carcasses in several countries. Its use for this purpose began in the 1950s and extends to the present, with enhancements that ensure an accuracy of over $50 \%$ in ultrasound and postslaughter carcass measurements (Crews et al., 2003). This accuracy was achieved by improving the equipment and training the technicians to collect and interpret the images; in addition, increased accuracy is significant for the selection of carcass characteristics and for animal sorting before slaughter (Stouffer, 2004).

Ultrasound measurements can be used along with other variables in the genetic analysis, improving the quality of the information generated (Bertrand, 2009). In this context, ultrasound and visual body score evaluations could be expressed as a single trait, for example, carcass merit, allowing simultaneous selection of morphological and carcass traits and facilitating the reporting to the farmers about genetic potential of the animal to meat production.

Correlations among ultrasound carcass traits are in accordance with those found in the literature for the Nellore breed, with little or no correlation between ribeye area, backfat thickness, and rump fat thickness (Yokoo et al., 2008; Zuin et al., 2012, Grosso et al., 2014). These correlations point out that, in this breed, selecting for larger ribeye areas is not related to a reduction in subcutaneous fat, and thus the genetic selection of both traits can be performed simultaneously, within the same herd.

The genetic correlations of backfat thickness and rump fat thickness with frame were low or close to zero, indicating that in the Nellore breed the selection for finishing precocity may not influence body size. These results differ from those described in the literature stating that selection based on body size increase could lead to late-maturing cattle (Pereira et al., 2001; Riley et al., 2002; Shiotsuki et al., 2009; Yokoo et al., 2010; Ferriani et al., 2013).

The low correlation of frame with backfat and rump fat thickness might be due to the low variation of these traits found in the studied herds, which may have influenced the relationships between variables. This warrants further investigation of these correlations in other Nellore herds.

\section{Genetic Progress}

Results of this study point out a low genetic progress for the traits evaluated, with only the visual body scores presenting a genetic progress greater than $0.5 \%$. The ultrasound carcass traits, frame, and rump traits, presented genetic progress close to zero, with no re- 
markable changes over the study period. These results are below those expected by the beef cattle breeding programs, which, according to Korver et al. (1988), Dillon et al. (2006), and Garrick and Ruvinsky (2014), should approximate $1 \%$ per year.

Visual body scores presented greater genetic progress than the other traits evaluated in this study. This is probably because selection for carcass and body structure in the studied herds was based on visual body scores, and changes in such traits were not reflected in significant changes in the ultrasound carcass traits evaluated.

Genetic progress can be improved by changing heritability estimates, generation intervals, and selection pressures in the population (Oliveira and Lôbo, 1995). However, changing selection pressure in the population will have the disadvantage of accentuating the undesirable effects due to the correlations among the traits. One example is the positive but undesirable correlation of increased muscling and ribeye area with frame.

The low and negative genetic trend found for frame in the present study might be desirable because there is no need to increase the body size, given its disadvantages in terms of the maintenance requirements for large framed cattle (Berg and Butterfield, 1976). As expected due to their high genetic correlation with frame, rump width and rump length also showed no significant increase in the genetic progress.

In contrast, the progress for muscling was expected to be greater due to its inclusion in the selection index of the herds studied (Brumatti et al., 2011). In beef cattle herds, the main objective is to produce animals with higher edible meat yield and better subcutaneous fat deposition, as these traits add value to the animals and increase profitability to producers (Pinheiro et al., 2011). Thus, the selection criteria in these herds should include some carcass traits, aiming to achieve greater economic incomes in beef cattle productions systems (Wilson, 1992; Reverter et al., 2000; Formigoni, 2002; Brumatti et al., 2011).

The equity in the genetic progress of conformation, precocity, and muscularity might be a reflection of the high genetic correlation found between these variables resulting in their similar genetic progress.

Carcass traits evaluated by ultrasound presented a low genetic progress, with increases below $0.05 \%$. This result may be due to several factors, including the low correlation between ribeye area and muscularity. In contrast, the heritability of muscularity is smaller than that of the ribeye area. This suggests that using ultrasound measurements instead of visual body scores in the selection for muscularity could result in greater genetic progress. The low-scored genetic trend for backfat thickness and rump fat thickness suggests that selection for precocity on fat deposition by using visual body scores is not effective.

Sasaki et al. (2006) evaluated the genetic trend of carcass characteristics of Japanese Black cattle during 3 periods, each comprising a different methodology: visual body score selection in the first; progeny tests in the second; and progeny tests and BLUP in the third. In the last 2 periods, carcass traits were directly collected between the sixth and seventh ribs. During the first period, the authors found genetic progressions ranging from -0.056 to $0.026 \mathrm{~cm}^{2}$ per year for ribeye area and 0.000 to $0.086 \mathrm{~mm}$ per year for backfat thickness, with the inclusion of more accurate genetic evaluations in the third period, genetic progression increased from 0.040 to $0.980 \mathrm{~cm}^{2}$ per year for ribeye area and 0.005 to $0.184 \mathrm{~mm}$ per year for backfat thickness, confirming the need for robust and accurate tools to collect data and increase genetic progress. Robinson et al. (1993) evaluated Angus, Hereford, and Polled Hereford animals using ultrasound and reported an annual increase of 1.65 $\mathrm{cm}^{2}, 0.18 \mathrm{~mm}$, and $0.09 \mathrm{~mm}$ in ribeye area, backfat thickness, and rump fat thickness, respectively.

The values obtained by Robinson et al. (1993) and Sasaki et al. (2006) were greater than those found in this study; however, the Nellore cattle considered in this study were mainly grass fed, which leads to lower growth rates and lower body fat (Ferraz and Felício, 2010). However, when comparing different herds, we must also consider the selection pressure exerted on the characteristics being examined (Oliveira and Lôbo, 1995)

The results reported in the present study show the importance of knowing the genetic correlations between the traits chosen for genetic selection to direct the efforts of genetic selection toward its goals. Furthermore, evaluating the genetic trend in the selected traits is fundamental for monitoring the progress and the effectiveness of the tools adopted.

The selection for some traits may not result in the desired genetic evolution in the herd because of the low heritability of traits or the employment of less effective selection tools. In addition, this slow genetic progress can be accompanied by unwanted correlated responses that, in turn, might compromise traits that are not a priority in genetic selection but are important for the beef cattle production, e.g., subcutaneous fat.

In conclusion, carcass traits evaluated by ultrasound, body measurements, and visual body scores are eligible for selection and can be used in genetic improvement programs of Nellore cattle. However, genetic trends and correlations among traits indicate that selection for carcass characteristics based on visual body scores can result in a lower genetic progress when compared to that performed by ultrasonography. 


\section{LITERATURE CITED}

Berg, R. T., and R. M. Butterfield. 1976. New concepts of cattle growth. Sydney Univ. Press, Sydney, New South Wales, Australia.

Bertrand, J. K. 2009. Using actual and ultrasound carcass information in beef genetic evaluation programs. R. Bras. Zootec. 38:58-63.

BIF. 2010. Guidelines for uniform beef improvement programs. Beef Improv. Fed., North Carolina State Univ., Raleigh.

Boligon, A. A., M. E. Z. Mercadante, and L. G. Albuquerque. 2011. Genetic associations of conformation, finishing precocity and muscling visual scores with mature weight in Nelore cattle. Livest. Sci. 135:238-243.

Bonin, M. N. 2012. Evaluation of growth and beef quality traits in lineages and representative Nellore sires, using ultrasound, video image analysis and NIRS measurements. PhD Diss. Univ. de São Paulo, Pirassununga, Brazil.

Bonin, M. N., J. B. S. Ferraz, J. P. Eler, F. M. Rezende, D. C. Cucco, M. E. Carvalho, R. C. G. Silva, R. C. Gomes, and E. C. M. Oliveira. 2014. Sire effects on carcass and meat quality traits of young Nellore bulls. Genet. Mol. Res. 13:3250-3264.

Brumatti, R. C., J. B. S. Ferraz, J. P. Eler, and I. B. Formigonni. 2011. Development of selection index in beef cattle under the focus of a bio-economic model. Arch. Zootec. 60:205-213.

Buchanan, D. S., and A. C. Clutter. 1989. Animal breeding: Principles and applications, 2nd ed. Board of Regents, Oklahoma State Univ., Stillwater.

Burrow, H. M., S. S. Moore, D. J. Johnston, W. Barendse, and B. M. Bindon. 2001. Quantitative and molecular genetic influences on properties of beef: A review. Aust. J. Exp. Agric. 41:893-919.

Caetano, S. L., R. P. Savegnago, A. A. Boligon, S. B. Ramos, T. C. S. Chud, R. B. Lôbo, and D. P. Munari. 2013. Estimates of genetic parameters for carcass, growth, and reproductive traits in Nellore cattle. Livest. Sci. 155:1-7.

Crews, D. H., Jr., E. J. Pollak, R. L. Weaber, R. L. Quaas, and R. J. Lipsey. 2003. Genetic parameters for carcass traits and their live animal indicators in Simmental cattle. J. Anim. Sci. 81:1427-1433.

Crouse, J. D., L. V. Cundiff, R. M. Koch, M. Koohmaraie, and S. C. Seideman. 1989. Comparisons of Bos indicus and Bos taurus inheritance for carcass beef characteristics and meat palatability. J. Anim. Sci. 67:2661-2668.

Dillon, P., D. P. Berry, R. D. Evans, F. Buckley, and B. Horan. 2006. Consequences of genetic selection for increased milk production in European seasonal pasture based systems of milk production. Livest. Sci. 99:141-158.

Falconer, D. S., and T. F. C. Mackey. 1996. Introduction to quantitative genetics. 4th ed. Longmans Green, Harlow, UK.

Faria, C. U., C. U. Magnabosco, L. G. Albuquerque, L. A. F. Bezerra, and R. B. Lôbo. 2009. Genetic correlation estimates between visual scores and carcass traits measured by ultrasound in Nellore cattle using linear-threshold Bayesian models. R. Bras. Zootec. 38:2144-2151.

Ferraz, J. B. S., and P. E. Felício. 2010. Production systems- An example from Brazil. Meat Sci. 84:238-243.

Ferriani, L., L. G. Albuquerque, F. S. B. Baldi, G. C. Venturini, A. B. Bignardi, J. A. I. I. V. Silva, T. C. S. Chud, D. P. Munari, and J. A. Oliveira. 2013. Genetic parameters of carcass and growth traits of Nellore cattle. Arch. Zootec. 62:123-129.

Formigoni, I. B. 2002. Estimação de valores econômicos para características componentes de índices de seleção em bovinos de corte (in Portuguese). MS Thesis. Univ. de São Paulo, Pirassununga, Brazil.

Garrick, D. G., and A. Ruvinsky. 2014. The genetics of cattle. 2nd ed. CABI Publishing, New York.
Groeneveld, E. 2006. PEST user's manual. Inst. of Anim. Sci., Mariensee, Germany.

Groeneveld, E., M. Kovac, and N. Mielenz. 2008. VCE User's guide and reference manual. Version 6.0. Dep. of Anim. Sci., Univ. of Illinois, Urbana.

Grosso, J. L. B. M., G. A. Oliveira Jr., I. R. Menezes, E. C. Mattos, J. B. S. Ferraz, and J. P. Eler. 2014. Genetic parameters for body conformation scores and carcass traits measured by real-time ultrasound in Nellore cattle. In: Proc. 10th World Congr. Genet. Appl. Livest. Prod., Vancouver, British Columbia, Canada, p. 718.

Henderson, C. R. 1975. Best linear unbiased estimation and prediction under a selection model. Biometrics 31:423-447.

Horimoto, A. R. V. R., J. B. S. Ferraz, J. C. C. Balieiro, and J. P. Eler. 2006. Estimation of genetic parameters for a new model for defining body structure scores (frame scores) in Nellore cattle. Genet. Mol. Res. 5:828-836.

Horimoto, A. R. V. R., J. B. S. Ferraz, J. C. C. Balieiro, and J. P. Eler. 2007. Phenotypic and genetic correlations for body structure scores (frame) with productive traits and index for CEIP classification in Nellore beef cattle. Genet. Mol. Res. 6:188-196.

King, D. A., M. E. Dikeman, T. L. Wheeler, C. L. Kastner, and M. Koohmaraie. 2003. Chilling and cooking rate effects on some myofibrillar determinants of tenderness of beef. J. Anim. Sci. 81:1473-1481.

Koohmaraie, M., S. C. Seideman, and J. D. Crouse. 1988. Effect of subcutaneous fat and high temperature conditioning on bovine meat tenderness. Meat Sci. 23:99-109.

Korver, S., H. A. M. van der Steen, J. A. M. van Arendonk, H. Bakker, E. W. Brascamp, and J. Dommerholt. 1988. Advances in animal breeding. Pudoc, Wageningen, the Netherlands.

Koury Filho, W., L. G. Albuquerque, S. Forni, J. A. V. Silva, II, M. J. Yokoo, and M. M. Alencar. 2010. Genetic parameters estimates for visual scores and their association with body weight in beef cattle. R. Bras. Zootec. 39:1015-1022.

Lawrence, T. L. J., and V. R. Fowler. 2002. Growth of farm animals. 2nd ed. CABI Publishing, New York.

Long, R. A. 1971. The Ankony scoring system-Its uses in herd improvement. Ankony Angus Corporation, Grand Junction, CO.

Marques, E. G., C. U. Magnabosco, F. B. Lopes, and M. C. Silva. 2013. Estimate the genetic parameters of growth characteristics, carcass and scrotal perimeter in Nellore evaluated in weight gain performance test in feedlot (in Portuguese). Biosci. J. 29:159-167.

May, S. G., W. L. Mies, J. W. Edwards, F. L. Williams, J. W. Wise, J. J. Harris, J. W. Savell, and H. R. Cross. 1992. Effect of frame size, muscle score, and external fatness on live and carcass value of beef cattle. J. Anim. Sci. 70:3311-3316.

McKeith, F. K., J. W. Savell, G. C. Smith, T. R. Dutson, and Z. L. Carpenter. 1985. Tenderness of major muscles from three breedtypes of cattle at different times-on-feed. Meat Sci. 13:151-166.

Neumaier, A., and E. Groeneveld. 1998. Restricted maximum likelihood estimation of covariances in sparse linear models. Genet. Sel. Evol. 30:3-26.

Oliveira, H. N., and R. B. Lôbo. 1995. Use of progeny testing in beef cattle: Prediction of genetic gain in a Nelore cattle breeding program. Rev. Bras. Genet. 18:207-214.

Oliveira, P. S., M. N. Bonin, D. C. Cucco, J. P. Eler, and J. B. S. Ferraz. 2013. Building a low cost instrument for measurement of important morphological measures for animal production. Livest. Res. Rural Dev. 25:40.

Pereira, E., J.P. Eler, and J.B.S. Ferraz. 2001. Genetic analysis of some reproductive traits and their relationships with weight traits in Nellore cattle. Arq. Bras. Med. Vet. Zootec. 53:720-727. 
Pereira, M. C., M. J. Yokoo, A. B. Bignardi, J. C. Sesana, and L. G. Albuquerque. 2010. Hip height and its relationships with reproductive and growth traits in Nelore cattle. Pesqi. Agropecu. Bras. 45:613-620.

Perkins, T. L., R. D. Green, K. E. Hamlin, H. H. Shepard, and M. F. Miller. 1992. Ultrasonic prediction of carcass merit in beef cattle: Evaluation of technician effects on ultrasonic estimates of carcass fat thickness and longissumus muscle area. J. Anim. Sci. 70:2758-2765.

Pinheiro, T. R., M. E. Mercadante, L. G. Albuquerque, J. N. Cyrillo, and R. H. Branco. 2011. Phenotypic and genetic parameters compared during repeated measures of longissimus muscle area and subcutaneous fat thickness in Nelore cattle. Genet. Mol. Res. 10:2944-2952.

Reverter, A., D. J. Johnston, H.-U. Graser, M. L. Wollcott, and W. H. Upton. 2000. Genetic analisys of live-animal ultrasound and abattoir carcass traits in Australian Angus and Hereford cattle. J. Anim. Sci. 78:1786-1795.

Riley, D. G., C. C. Chase Jr., A. C. Hammond, R. L. West, D. D. Johnson, T. A. Olson, and S. W. Coleman. 2002. Estimated genetic parameters for carcass traits of Brahman cattle. J. Anim. Sci. 80:955-962.

Riley, D. G., D. D. Johnson, C. C. Chase, Jr., R. L. West, S. W. Coleman, T. A. Olson, and A. C. Hammond. 2005. Factors influencing tenderness in steaks from Brahman cattle. Meat Sci. 70:347-356.

Robinson, D. L., K. Hammond, and C. A. McDonald. 1993. Live animal measurement of carcass traits: Estimation of genetic parameters for beef cattle. J. Anim. Sci. 71:1128-1135.

Santiago, A. A. 1987. Gado Nelore: 100 anos de seleção (in Portuguese). Ed. dos Criadores, São Paulo, SP, Brazil.

Sasaki, Y., T. Miyake, C. Gaillard, T. Oguni, M. Matsumoto, M. Ito, T. Kurahara, Y. Sasae, K. Fujinaka, S. Ohtagaki, and T. Dougo. 2006. Comparison of genetic gains per year for carcass traits among breeding programs in the Japanese Brown and the Japanese Black cattle. J. Anim. Sci. 84:317-323.

Sherbeck, J. A., J. D. Tatum, T. G. Field, J. B. Morgan, and G. C. Smith. 1996. Effect of phenotypic expression of Brahman breeding on marbling and tenderness traits. J. Anim. Sci. 74:304-309.
Shiotsuki, L., J. A. V. Silva, II, H. Tonhati, and L. G. Albuquerque. 2009. Genetic associations of sexual precocity with growth traits and visual scores of conformation, finishing, and muscling in Nelore cattle. J. Anim. Sci. 87:1591-1597.

Stouffer, J. R. 2004. History of ultrasound in animal science. J. Ultrasound Med. 23:577-584.

Thompson, J. 2002. Managing meat tenderness. Meat Sci. 62:295-308.

UGC. 2012. Quality data for genetic evaluation. 2012 ed. Ultrasound Guidelines Council (UGC). http://ultrasoundbeef. com/Resources_for_Techs.html. (Accessed 24 July 2015.)

USDA. 2015. Production, supply and distribution onlineCustom Query. http://apps.fas.usda.gov/psdonline/psdquery. aspx (Accessed 17 April 2015.)

Whipple, G., M. Koohmaraie, M. E. Dikeman, J. D. Crouse, M. C. Hunt, and R. D. Klemm. 1990. Evaluation of attributes that affect longissimus muscle tenderness in Bos taurus and Bos indicus cattle. J. Anim. Sci. 68:2716-2728.

Wilson, D. E. 1992. Application of ultrasound for genetic improvement. J. Anim. Sci. 70:973-983.

Wulf, D. M., and J. K. Page. 2000. Using measurements of muscle color, $\mathrm{pH}$, and electrical impedance to augment the current USDA beef quality grading standards and improve the accuracy and precision of sorting carcasses into palatability groups. J. Anim. Sci. 78:2595-2607.

Yokoo, M. J., L. G. Albuquerque, R. B. Lôbo, L. A. F. Bezerra, F. R. C. Araujo, J. A. V. Silva, II, and R. D. Sainz. 2008. Genetic and environmental factors affecting ultrasound measures of longissimus muscle area and backfat thickness in Nelore cattle. Livest. Sci. 117:147-154.

Yokoo, M. J., L. G. Albuquerque, R. B. Lôbo, R. D. Sainz, J. M. Carneiro, Jr., L. A. F. Bezerra, and F. R. C. Araujo. 2007. Estimation of genetic parameters for hip height, weight and scrotal circumference in Nelore cattle. R. Bras. Zootec. 36:1761-1768.

Yokoo, M. J., R. B. Lôbo, F. R. C. Araujo, L. A. F. Bezerra, R. D. Sainz, and L. G. Albuquerque. 2010. Genetic associations between carcass traits measured by real-time ultrasound and scrotal circumference and growth traits in Nelore cattle. J. Anim. Sci. 88:52-58.

Zuin, R. G., M.E. Buzanskas, S. L. Caetano, G. C. Venturini, D. G. F. Guidolin, D. A. Grossi, T. C. S. Chud, C. C. P. Paz, R. B. Lôbo, and D. P. Munari. 2012. Genetic analysis on growth and carcass traits in Nelore cattle. Meat Sci. 91:352-357. 